\title{
Role of Auto-inhibitors on Mycelial Growth and Dimorphism of Glomerella cingulata
}

\author{
By B. T. LINGAPPA AND YAMUNA LINGAPPA \\ College of the Holy Cross, Worcester, Massachusetts or6ı, U.S.A.
}

(Accepted for publication 26 November 1968)

\begin{abstract}
SUMMAR Y
Crowding of conidia of Glomerella cingulata on potato sucrose agar led to a yeast-like growth of closely opposing and sandwiched streaks whereas the outer edges of the streaks developed fluffy mycelia. In liquid cultures increasing the initial conidial inocula increased the development of conidia and correspondingly decreased the mycelia. Normally, conidia germinate to produce germ tubes which branch and develop into cottony mycelia(M phase). Crowded conditions ( 3000 or more conidia $/ \mathrm{mm} .^{2}$ or about $2 \mathrm{million} / \mathrm{ml}$.) gave rise to secondary conidia with or without short hyphae or pseudomycelia: the yeast-like cultures ( $\mathrm{Y}$ phase). In addition to crowding, thorough aeration, protection from light radiation below $500 \mathrm{~m} \mu$ and a temperature of incubation $c .2 \mathrm{I}^{\circ}$ favoured the $\mathrm{Y}$ phase development on appropriate media. Bicarbonate or $\mathrm{CO}_{2}$ did not induce $\mathrm{Y}$ phase development. Washings and basic $\mathrm{CH}_{2} \mathrm{Cl}_{2}$ extracts of conidia (which contained auto-inhibitors) induced preferential development of conidia with concomitant decrease in mycelia. Diffusible substances associated with the conidia, in appropriate concentrations, are considered responsible for inhibition of mycelia and preferential development of Y phase.
\end{abstract}

\section{INTRODUCTION}

Glomerella cingulata produces conidia and abundant mycelia on common laboratory media. The conidia germinate readily but germination is reduced in proportion to the density of conidia; this inhibition is due to diffusible substances present in the conidia (Lingappa \& Lingappa, I966a). Substances which decrease, retard or inhibit the growth and development of the organism producing them may be designated as auto-inhibitors, self-inhibitors, auto-antibiotics, or inhibitory autobiotics (Lingappa \& Lingappa, I $966 b, 1967)$. In $G$. cingulata, inhibitors of germination were present in considerable amount in the conidia but not in the mycelia. Normally, conidia of G. cingulata germinate to produce extensively branching mycelia which bear conidia on aerial conidiophores or in large masses in compact acervuli. Conidia were also capable of germinating into secondary conidia with an abridged or a lack of development of mycelial phase. Colonies derived from the proliferation of secondary conidia were nonmycelial and yeast-like: G. cingulata was dimorphic, capable of developing mycelial (M) or yeastlike (Y) growth. Since factors inducing this dimorphism have not been reported for any other fungi, we have reported our findings on growth and ldimorphism of G. cingulata in this paper. 


\section{METHODS}

Cultures of Glomerella cingulata were grown in shaken Neurospora minimal medium (NM) (Difco Laboratories, Detroit, Michigan) or in potato sucrose broth (PS). Potato broth was prepared as follows: $220 \mathrm{~g}$. sound, peeled and washed potatoes were sliced into $2 \mathrm{~cm}$. cubes and autoclaved with I 1 . distilled water for $20 \mathrm{~min}$. at I $5 \mathrm{lb} / \mathrm{in}$. and the extract was strained, while steaming hot, through Miracloth (Chicopee Mfg. Co., Milltown, N. J.) without squeezing. The volume was made up to I 1 . after addition of sucrose $(5.6 \%, \mathrm{w} / \mathrm{v})$. Broth made by this procedure contained $c .0 .6 \%$ $(\mathrm{w} / \mathrm{v})$ potato solids, was very light coloured, and the preparations were reproducible. Erlenmeyer flasks $(500 \mathrm{ml}$.) containing $150 \mathrm{ml}$. broth were inoculated with $10 \mathrm{ml}$. inocula (50 mg. conidia) and shaken in PS at $2 \mathrm{I}^{\circ}$ for $7-10$ days. The conidia were separated from mycelia by straining the cultures through Miracloth and thoroughly rinsing the mycelia with water. Dry weights of duplicate samples of mycelia and conidia were determined. The cultures were extracted for inhibitors as previously reported (Lingappa \& Lingappa, I $966 a$ ). Acidified conidial suspensions were extracted by shaking with light petroleum (b.p. $30-80^{\circ}$ ). The defatted slurry was made basic and extracted with $\mathrm{CHCl}_{3}$. Crude bases from $\mathrm{CHCl}_{3}$ extracts contained auto-inhibitors. Additional procedures are described under appropriate experiments.

\section{RESULTS}

General observation on dimorphism. Glomerella cingulata could be grown in either cottony mycelial $(\mathrm{M})$ or yeast-like conidial $(\mathrm{Y})$ cultures in both solid and liquid media. Whereas mycelial development was very readily obtained, the Y phase developed only under specified conditions. At $21^{\circ}-25^{\circ}$, when cultured in PS or NM, this fungus produced both mycelia and conidia in varying proportions. Therefore we investigated the role of several of the nutritional and environmental factors that appeared to influence $\mathrm{M}$ or $\mathrm{Y}$ phase development. In some specially designed cultures, the influence of auto-inhibition on mycelial development was striking (Pl. I). On PS agar $(2 \%, w / v)$ slopes, subcultures became mycelial unless the initial conidial inocula were streaked densely, 3000 or more conidia/mm. ${ }^{2}$ (Pl. I, fig. 4). On agar slopes subcultures were yeast-like on the shallow top portions and more or less mycelial on the deep ends, especially when slopes were made with larger quantities of media. Agar slopes made of $2 \mathrm{ml}$. media and densely inoculated with conidia developed yeast-like whereas cultures similarly inoculated on slopes made of $6 \mathrm{ml}$. media were mycelial(P1. I, fig. 4). Condensed water on the bottom of the slopes also increased mycelia. Cultures became mycelial at temperatures higher than $25^{\circ}$ and when exposed to incandescent light or daylight.

Mat, tile, V, Z, and other designs of streak cultures were made to observe the effect of the distance between opposing streaks on development of streaked conidia on PS agar plates. Plate I, fig. I, 4 show that the edges of streak cultures in close opposition did not develop mycelia and remained yeast-like whereas the exposed outer edges developed cottony mycelia. The upper edge of Pl. I, fig. 3, I developed only scanty mycelia and the hyphae bore terminal and lateral conidia whereas the advancing margin of streak 3 in Pl. I, fig. 3 remained vegetative (Pl. 2, fig. 14, 15, I6). These plates suggested that some kind of intraspecific or homotypic interactions might be leading to 
the development of $\mathrm{Y}$ phase and the inhibition of $\mathbf{M}$ phase. This differential development appeared to be due to concentration gradients of diffusible metabolites associated with the conidial inocula. Samples taken from cultures inoculated with dense inocula ( 2 million or more conidia $/ \mathrm{ml}$.) showed various examples of differentiation of germ tubes into secondary conidia (Pl. 2). Differentiation of germ tubes into conidia occurred as the tubes were emerging from the germinating conidia or after considerable filamentous growth as pseudomycelia. In liquid cultures the relative development of $\mathrm{M}$ and $\mathrm{Y}$ phases was quantitatively determined by separating conidia from mycelia. Consequently, differences between $\mathrm{M}$ and $\mathrm{Y}$ phase could be measured by numbers and dry weights of conidia. These procedures were used in the following experiments.

Table I. Influence of concentration of sugar and initial inocula on preferential development of conidia of Glomerella cingulata

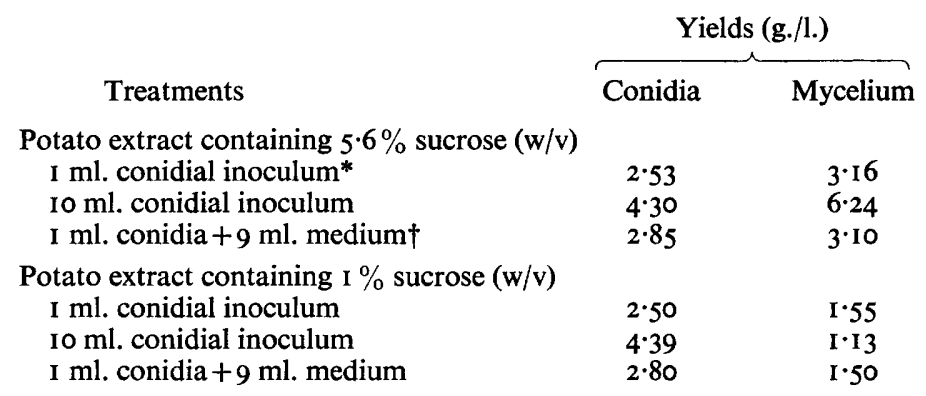

* Potato extracts contained $0.4 \%$ potato solids (dry wt). Inoculum contained $4 \mathrm{mg}$. conidia $/ \mathrm{ml}$. along with media residues.

$\uparrow$ Supernatant medium of the inoculum, without conidia, obtained by settling conidia for 3 hr at $4^{\circ}$.

Influence of amount of initial inoculum. The conidia settled down in the flasks of shaken cultures of Glomerella cingulata when left still on shelves for 3-4 hr. The supernatent media and myceliar fragments were asceptically removed leaving about ro $\mathrm{ml}$. fluids to resuspend the settled conidia. The entire suspension of conidia of a flask was transferred to a flask containing $150 \mathrm{ml}$. PS medium and shaken for 8-10 days at $2 \mathrm{I}^{\circ}$. This conidial culture was propagated by inoculating $10 \mathrm{ml}$. samples into fresh media to be used as conidial inocula. Cultures developed more conidia when started with Io $\mathrm{ml}$. than with I ml. conidial inocula (Table I). Increasing sucrose in potato broth increased yield of both conidia and mycelia. But the relative abundance of conidia compared to mycelium could be attributed to larger inocula. Flasks inoculated with $1 \mathrm{ml}$. conidial cultures and supplemented with $9 \mathrm{ml}$. culture medium without conidia yielded slightly more conidia than those that received only $\mathrm{I}$ ml. conidial inocula, and therefore preferential development of conidia appeared to be influenced mostly, if not entirely, by the conidial inocula. The supernatant medium also had some influence. Increasing the initial conidial inocula to $2 \cdot 8 \mathrm{~g}$. $/ 1$. (w/v) increased the formation of conidia with a concomitant decrease in mycelia (Fig. I). This differential response to density of inocula was even more striking in potato broths containing less sucrose or none at all (Table 2).

Influence of media. Table 2 indicates that potato extract as such was the most effective for preferential development of conidia. Dehydrated potato extract was less than half as effective as freshly prepared broths. These and other results led to the improvement 
of potato extracts by preparing them by autoclaving rather than by boiling over a flame. Neurospora minimal medium was a very good medium for mycelial development but not for formation of conidia.

Influence of aeration and of light. Table 3 showed that, compared to still cultures, aeration by shaking ( 120 strokes/min.) more than doubled the formation of conidia

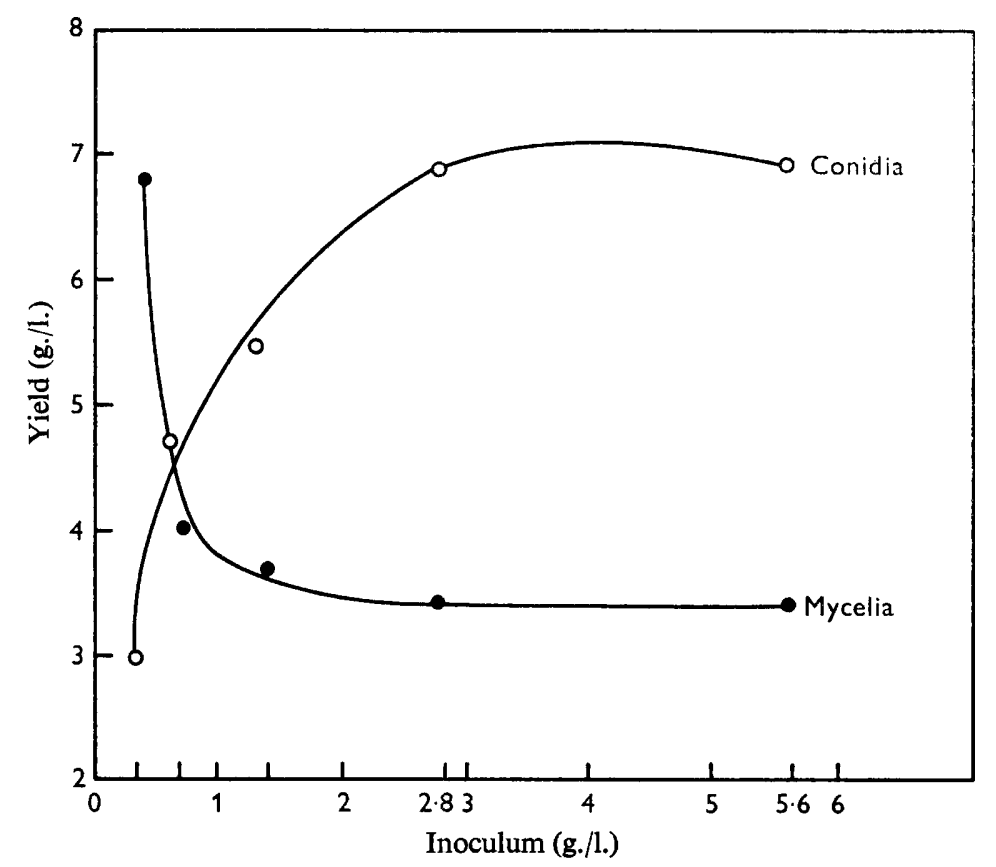

Fig. I. Effect of increased inoculum of conidia of Glomerella cingulata on differential development into conidial or mycelial cultures. $150 \mathrm{ml}$. flask cultures were shaken in PS media for 8 days at $21^{\circ}$.

Table 2. Influence of media on relative development of conidia and mycelium of Glomerella cingulata

Media

A. Potato extract without additives*

Potato extract $+I \%$ sucrose

Potato extract $+5 \%$ sucrose

Difco PE $\left(0.4 \% \mathrm{w} / \mathrm{v}\right.$ in $\left.\mathrm{H}_{2} \mathrm{O}\right)+5 \%$ sucrose

Difco PE $\left(0.8 \% \mathrm{w} / \mathrm{v}\right.$ in $\left.\mathrm{H}_{2} \mathrm{O}\right)+5 \%$ sucrose

B. Neurospora minimal medium (Difco)

$$
\begin{aligned}
& \text { NM }+2 \% \text { sucrose } \\
& \text { NM }+4 \% \text { sucrose } \\
& \text { NM }+8 \% \text { sucrose } \\
& \text { NM }+10 \% \text { sucrose }
\end{aligned}
$$

$\overbrace{\text { Conidia }}^{2} \begin{array}{cc}\text { Mycelium } \\ 3.05 & 0.30 \\ 5.22 & 1.42 \\ 7.53 & 6.70 \\ 2.78 & 2.48 \\ 3.30 & 2.83\end{array}$

$\begin{array}{rr}I \cdot 24 & 4 \cdot 25 \\ 2 \cdot 89 & 11 \cdot 54 \\ 0 \cdot 95 & 18 \cdot 45 \\ I \cdot 17 & 20 \cdot 17\end{array}$

* Freshly prepared and containing $0.6 \%$ potato solids. PE signifies dehydrated potato extract from Difco Laboratories, Detroit, Michigan. NM signifies neurospora minimal medium; above $8 \%$ sucrose the medium became viscous and quantitative recovery of conidia became difficult. 
with accompanying decrease in mycelia. Visible light promoted mycelial growth and decreased conidia. Exclusion of visible light by growing in a dark chamber, or covering with black plastic film or paper, or in dark red-coloured Ray-Sorb flasks resulted in increased development of conidia. Red-coloured flasks filter out lower wavelength light radiation but transmit red and far red lights. Lower wavelength light thus appeared to be inhibitory to development of conidia.

Table 3. Influence of aeration and light on relative development of conidia and mycelia of Glomerella cingulata

\begin{tabular}{lcc} 
& \multicolumn{2}{c}{ Yields (g./1.) } \\
\cline { 2 - 3 } Conidia & Mycelium \\
Shaken in clear Kimax flasks in light* & $3 \cdot 47$ & $3 \cdot 76$ \\
Shaken in clear Kimax flasks in dark & $4 \cdot 35$ & $\mathbf{I} \cdot 44$ \\
Still culture in Kimax flasks in dark $\dagger$ & $\mathrm{I} \cdot 80$ & $7 \cdot 00$ \\
Still culture in Kimax flasks in light & $\mathrm{I} \cdot 50$ & $6 \cdot 40$ \\
Still culture in Roux bottles in dark & $3 \cdot 28$ & $6 \cdot 70$ \\
Still culture in Roux bottles in light & $2 \cdot 80$ & $6 \cdot 80$ \\
Shaken in Ray-Sorb flasks $\ddagger$ & $4 \cdot 18$ & $\mathrm{I} \cdot 08$
\end{tabular}

* Incandescent light providing $c .65 \mathrm{ft}-\mathrm{c}$.

† Still cultures prepared and inoculated like other cultures but left on shelves unshaken. Still cultures in flasks differed from those in Roux bottles in having more than twice the depth of the media and only one-third the surface exposed to air, i.e. Roux bottles contained the same amount of media but in shallow layers.

¥ Kimax and Ray-Sorb are products of Owens-Illinois, Toledo, Ohio. Ray-Sorb flasks are redcoloured and transmit no light at $300 \mathrm{~m} \mu, \mathrm{I} \%$ at $400 \mathrm{~m} \mu$ and $4 \%$ at $500 \mathrm{~m} \mu$. They were in a lighted cabinet. Yields of still Ray-Sorb flasks were similar to those of (clear) Kimax flasks.

\section{Table 4. Effects of addition of conidia, washings and extracts of conidia on development of conidia and mycelia of Glomerella cingulata}

\section{Materials added}

Medium without additives*

Medium $+300 \mathrm{mg}$. washings $\dagger$

Medium + $100 \mathrm{mg}$. conidia

Medium $+200 \mathrm{mg}$. conidia

Medium + $100 \mathrm{mg}$. conidia + $20 \mathrm{mg} . \mathrm{E}+$

Medium $+100 \mathrm{mg}$. conidia + $40 \mathrm{mg}$. E

$\begin{array}{lr}\text { Conidia } & \text { Mycelium } \\ 4.68 & 3.21 \\ 5.87 & 1 \cdot 20 \\ 4.84 & 4.83 \\ 5.49 & 4.46 \\ 5.32 & 3.6 \mathrm{I} \\ 5.90 & 3.50\end{array}$

$\begin{array}{cc}\times 10^{-6} / \mathrm{ml} . & \times 10^{-6} / \mathrm{mg} . \\ - & - \\ - & - \\ 78 & 16 \cdot 2 \\ 85 & 15 \cdot 6 \\ 124 & 22 \cdot 0 \\ 168 & 25.6\end{array}$

* Potato sucrose broth (I $50 \mathrm{ml}$./flask) inoculated with $40 \mathrm{mg}$. conidial inoculum and shaken at $2 \mathrm{I}^{\circ}$. $\dagger 20 \mathrm{~g}$. freshly harvested conidia were rinsed in water and then shaken in $100 \mathrm{ml}$. water for $30 \mathrm{~min}$., centrifuged, filtered, partially evaporated and added to inoculated cultures.

$\ddagger \mathrm{E}$ is the extract of $20 \mathrm{~g}$. conidia obtained by $\mathrm{CH}_{2} \mathrm{Cl}_{2}$ extract of defatted conidia at $\mathrm{pH}$. This extract contained self-inhibitors of germination. Larger number of conidia was associated with smaller size, 5-8 $\times 6-16 \mu$; when produced in smaller numbers they were 10-26 $\mu$ long.

Influence of temperature. A series of flasks was inoculated with conidial inocula varying from 0.5 to $5.0 \mathrm{~g} . / 1$. and shaken at $2 \mathrm{I}^{\circ}$ and a similar set was shaken at $30^{\circ}$. Those at $21^{\circ}$ yielded increasing amounts of conidia, with corresponding decrease in mycelia, with increasing amounts of inoculum (Fig. I): $2 \cdot 8 \mathrm{~g}$./1. inoculum yielded $7 \mathrm{~g}$. conidia and $3.5 \mathrm{~g}$. mycelia/l. at $2 \mathrm{I}^{\circ}$ but at $30^{\circ}$ only $0.6-0.8 \mathrm{~g}$. of conidia and $\mathrm{II}-\mathrm{I} 3 \mathrm{~g}$. 
mycelia/l. appeared at all inoculum sizes. At $32^{\circ}$ conidia were not produced. Clearly the preferential development of conidia was modified by temperature. Measurable amounts of conidia were not produced below $18^{\circ}$. Therefore, all subsequent experiments were carried out in temperature controlled chambers at $2 \mathrm{I}^{\circ}$ without light which were most favourable for the development of conidial cultures.

Influence of addition of extracts of conidia. The,effects of addition of conidia, washings of conidia, and crude basic $\mathrm{CH}_{2} \mathrm{Cl}_{2}$ extracts of conidia of Glomerella cingulata on development of $\mathrm{M}$ and $\mathrm{Y}$ phases are summarized in Table 4. Increased yields of conidia were obtained when cultures were supplemented with washings of conidia or with extracts of conidia. These additives also influenced profoundly the number and size of the conidia. These observations indicated that the formative effect of conidial density was due to substances extractable from conidia.

Table 5. Effect of addition of potato constituents on development of conidia and mycelia of Glomerella cingulata

\begin{tabular}{|c|c|}
\hline & Yie \\
\hline Materials added & Conidia \\
\hline
\end{tabular}

\begin{tabular}{|c|c|c|}
\hline \multicolumn{3}{|c|}{ A. Effect of solanine* } \\
\hline \multicolumn{3}{|l|}{ In potato sucrose broth: } \\
\hline $2.5 \mathrm{~g}$. inoculum $/ \mathrm{l}$ & $5 \cdot 86$ & $3 \cdot 95$ \\
\hline $0.25 \mathrm{~g}$. inoculum $/ 1$ & $4 \cdot 19$ & $7 \cdot 02$ \\
\hline $0.25 \mathrm{~g}$. inoculum $/ 1 .+10^{-3} \mathrm{M}$-solanine & 3.50 & $8 \cdot 04$ \\
\hline \multicolumn{3}{|l|}{ In Neurospora minimal medium: } \\
\hline $2 \cdot 5 \mathrm{~g}$. inoculum $/ 1$. & $I \cdot 43$ & $3 \cdot 44$ \\
\hline $0.25 \mathrm{~g}$. inoculum $/ 1$ & 1.02 & $5 \cdot 10$ \\
\hline $2.5 \mathrm{~g}$. inoculum $/ \mathrm{l} .+\mathrm{IO}^{-2} \mathrm{M}$-solanine & 0.64 & 3.54 \\
\hline $2.5 \mathrm{~g}$. inoculum $/ 1 .+10^{-3} \mathrm{M}$-solanine & $1 \cdot 26$ & $5 \cdot 14$ \\
\hline $0.25 \mathrm{~g}$. inoculum $/ \mathrm{l} .+10^{-2} \mathrm{M}$-solanine & 0.29 & 4.53 \\
\hline $0.25 \mathrm{~g}$. inoculum $/ \mathrm{l} .+10^{-3} \mathrm{M}$-solanine & 0.98 & $5 \cdot 81$ \\
\hline \multicolumn{3}{|c|}{ B. Effect of ethanol extracts of potato } \\
\hline Potato broth without sucrose & $I \cdot 70$ & 0.56 \\
\hline Potato broth with sucrose $5 \%(\mathrm{w} / \mathrm{v})$ & 3.35 & 6.86 \\
\hline Neurospora minimal medium & $0 \cdot 10$ & $14 \cdot 67$ \\
\hline $\mathrm{NM}+135 \mathrm{mg} . / \mathrm{l}$. ethanol extract of potato & $2 \cdot 30$ & $6 \cdot 70$ \\
\hline $\mathrm{NM}+270 \mathrm{mg} . / 1$. ethanol extract of potato & $3 \cdot 20$ & $11 \cdot 62$ \\
\hline $\mathrm{NM}+540 \mathrm{mg} . / 1$. ethanol extract of potato & 0.90 & 13.03 \\
\hline
\end{tabular}

* Solanine was obtained from Aldrich Chemical Co., Milwaukee, Wisconsin.

$\dagger$ In experiments listed under part B of this table, flasks were inoculated with I ml. inoculum. Growth in potato broth media is given here to compare with that obtained in NM and in NM supplemented with the residues obtained by ethanolic extract of potato.

$\ddagger$ Residue obtained by evaporation of alcohol extract of $100 \mathrm{~g}$. dehydrated Difco potato extract, added into Difco Neurospora minimal medium (NM). The media contained $5 \%$ sucrose (w/v).

Role of constituents of potato extract. Potato extract was superior for conidial development of Glomerella cingulata, though Neurospora minimal medium gave the best vegetative growth. The materials in solvent extracts of conidia which stimulated the development of conidia may be alkaloids or related substances (Lingappa \& Lingappa, 1967). Potatoes contain several alkaloids, which are readily extracted by ethanol, solanine being the best known (Cromwell, 1955). Both pure solanine and the residue obtained by drying ethanol extract of potato were separately incorporated into cultures and examined for their influence on the development of conidia in NM medium (Table 5). 
Solanine was ineffective at lower concentrations and inhibitory at higher concentrations. Ethanol extractable materials from potato stimulated the development of conidia and at higher concentration inhibited the production of conidia but not mycelia. To what extent solanaceous alkaloids in the extracts were responsible for $Y$ phase development of $G$. cingulata is not clear.

Effect of carbon dioxide and bicarbonate. In any population density-dependent interactions $\mathrm{CO}_{2}$ may be involved. Flasks were fitted with rubber stoppers with inlet and outlet plugged glass tubes ending with soft rubber tubing. After inoculation of the freshly prepared media with conidial cultures, $\mathrm{CO}_{2}$ was bubbled through the media and, after saturation with $\mathrm{CO}_{2}$, the end tubes were folded, clamped and secured with tape. Below the clamps $5 \mathrm{~mm}$. vertical incisions served as safety valves for any build up of gases inside the flasks. Separate experiments with I, IO and $50 \%(\mathrm{v} / \mathrm{v}) \mathrm{CO}_{2}$ showed that $\mathrm{CO}_{2}$ concentration did not induce differential development of conidia. Well-aerated control cultures developed $\mathrm{Y}$ phase. To assess the role of bicarbonate, predetermined amounts of bicarbonate solution were added after inoculation using sterilizing filters in syringe holders. $\mathrm{NaHCO}_{3}$ between 0.5 and $40 \mathrm{mM}$ in both media did not favour the development of conidial cultures, but inhibited differentiation of conidia to a greater extent than it did the growth of mycelia.

\section{DISCUSSION}

Fungi pathogenic to man and animals which have yeast (Y) and mycelial (M) forms have been called dimorphic, having two forms (Ainsworth \& Bisby, 1950). However several plant pathogenic and saprophytic fungi exhibit $\mathbf{Y}$ and $\mathbf{M}$ forms (Roberts, 1946; Lodder \& Kreger-Van Rij, I952; Cooke, I962; Brandt, 1963; Haskins \& Spencer, 1967). Therefore, a dimorphic fungus is better defined as one in which a reversible transformation from a mycelial to a nonmycelial unicellular type of growth occurs (Cochrane, 1958). Our findings present a unique case of morphogenetic response dependent on population density of initial conidial inocula. In diverse groups of organisms, various morphogenetic responses to dense populations have been attributed to $\mathrm{CO}_{2}$. In Blastocladiales it is $\mathrm{CO}_{2}$ and/or bicarbonate, or visible light which determine the development of the sporangial types (Cantino, 1966). $\mathrm{CO}_{2}$ is also known to have a morphogenetic influence in Sporotrichum schenkii (Drouhet \& Mariat, 1952), Trichophyton mentagrophytes (Chin \& Knight, 1963), and Mucor rouxii (Bartnicki-Garcia, 1963). In Blastocladiella emersonii exogenous bicarbonate induces alternative metabolic pathways before the differentiation of sporangial types (Cantino, 1966). Incorporation of exogenous $\mathrm{CO}_{2}$ into key metabolic intermediates and their influence on the structure of cell walls might be controlling $\mathrm{Y}$ and $\mathrm{M}$ phase development in Mucor rouxii (Nickerson \& Bartnicki-Garcia, 1964). Exogenous incorporation of $\mathrm{CO}_{2}$ into several metabolic intermediates is known to occur in many different groups of organisms. Our results with different concentrations of $\mathrm{CO}_{2}$ and bicarbonate, however, did not implicate these in $\mathrm{Y}$ phase development of Glomerella cingulata.

Pine \& Peacock (1958) concluded that the conversion of M phase of Histoplasma capsulatum into $\mathrm{Y}$ phase required (I) a satisfactory growth requirement of the $\mathrm{Y}$ phase and (2) an inhibition of growth of $M$ phase without inhibition of conversion to $Y$ phase. Citric acid stimulated the $\mathrm{Y}$ phase of $H$. capsulatum and $\mathrm{Ca}$ and $\mathrm{Mg}$ annulled this effect. Differential toxicity of citric acid to $Y$ and $M$ phases was also influenced by temperature 
and by $\mathrm{Ca}, \mathrm{Mg}$ and $\mathrm{Zn}$. Differential requirements for trace metals or ability to compete for trace metals with citrate, modified by temperature, may influence development of $\mathrm{Y}$ or M phase of $H$. capsulatum. Langeron \& Guerra (1940) described Y and M phase development of Candida albicans on streaked cultures similar to those illustrated in Glomerella cingulata in this paper. They suggested a possible role of self-inhibitors and/or depletion of essential nutrients in the development of $Y$ phase. Fungi produce regulatory compounds that affect their growth and differentiation (Robbins, 1940; Stadler, I952; Banbury, 1955; Bistis, 1956). Conidial development of Colletotrichum lindemuthianum is enhanced by extracts of mycelia and conidia (Mathur, Barnett \& Lilly, I950). In G. cingulata, filtrates of perithecial cultures inhibited conidial development and filtrates of conidial cultures inhibited perithecial development (Wheeler, 1956). A hormonal substance produced in the culture media was responsible for induced selfing in G. cingulata (Driver \& Wheeler, I955). Endogenous inhibitors were not responsible for decreased production of tyrosinase by the mycelial cultures of G. cingulata grown on increasing amounts of media (Sussman, Coughey \& Strain, I955). A morphogenetic staling substance in the cultures of Fusarium oxysporum which in higher concentrations inhibited spore germination and induced autolysis has been described (Robinson \& Park, 1965). In G. cingulata we have reported the existence of self-inhibitors of germination of conidia in the washings and extracts of conidia (Lingappa \& Lingappa, 1966a, b). When similar washings and extracts of conidia were added, cultures developed into predominantly $\mathrm{Y}$ phase; the active materials were non-gaseous since the extracts were dried in a rotary evaporator at $15 \mathrm{~mm}$. pressure. This and other results reported here indicated that some diffusible products of metabolism associated with the conidia of G. cingulata induced its Y phase development. Possible non-gaseous metabolic products that may be expected in the washings and extracts of conidia are the various carboxylic, amino or fatty acids and compounds rich in SH groups (Nickerson \& Bartnicki-Garcia, 1964). The conidia were extracted to remove lipids and the extracts contained basic materials (Lingappa \& Lingappa, 1967) which were ninhydrin negative. Sulphur was not detected in sodium fusion products of the extracts prepared according to Shriner, Fuson \& Curtin (I956). Therefore, carboxylic, amino or fatty acids or $\mathrm{SH}$ compounds are not primarily responsible for the Y phase development. These extracts contained germination inhibitors but whether or not the same germination inhibitors were inducing dimorphism is not known. The crude ethanolic extracts of potato induced some preferential development of $\mathrm{Y}$ phase of $G$. cingulata which might be due to Solanium alkaloids, but the effect due to washings and extracts of conidia could not be due to this source because the conidia were washed free of all media. Development of $Y$ phase from the conidia of G. cingulata took place by differentiation of either the tips of germ tubes, or of lateral branches of pseudomycelia, or by direct budding, or by development of constriction of hyphae into monilial chains. Direct conversion of macroconidia of $H$. capsulatum into yeast cells by polar and non-polar budding, by formation of yeast cells from the tip of hyphae and by forming chains of monilial cells from hyphae, have been described by Pine \& Webster (1962). Turian \& Matikian (I966) also described budding of conidia and constriction and severence of preformed aerial hyphae in Neurospora. Functionally $\mathrm{Y}$ and $\mathrm{M}$ phases differ conspicuously in several respects including pathogenicity (Mackinnon, 1940). There is considerable evidence that the $\mathrm{Y}$ and $\mathrm{M}$ phases differ in their susceptibility to exogenous inhibitors (Pine \& Peacock, 1958; Brandt, 1963; 
Jillson \& Nickerson, 1948). Smut, rust and Taphrina fungi are mycelial in their host tissue and yeast-like in their development outside their host plants. Sporidia of Cronartium ribicola produced secondary sporidia up to six successive generations on water agar but on susceptible host needles the sporidia produced germ tubes to infect and develop the parasitic mycelial phase (Bega, 1960). The tendency to develop the $Y$ phase in many filamentous fungi seems advantageous in tiding over a brief period of unfavourable conditions during vegetative development and in greater dissemination (Clinton \& McCormick, 1919). Specific exogenous or endogenous factors may play a role in these developmental responses which have great survival value to the organism. Specific metabolites accumulating in the culture media are known to induce sporulation in several fungi (Trione, Leach \& Mutch, 1966). Recently, we have isolated two autoinhibitors from the cultures of Candida albicans, phenethylalcohol and tryptophol, which may be playing a role in dimorphic development of C. albicans (Lingappa et al. I968). The conidial extracts of $G$. cingulata contain auto-inhibitors of germination; whether the same inhibitors inhibit $M$ phase and induce $Y$ phase are not clear.

This work was partly supported by U.S. National Science Foundation, Research Grants, GB-645 and GB-3179. A Faculty Fellowship awarded (to B.T.L.) by the College of the Holy Cross facilitated the completion of this paper.

\section{REFERENCES}

Ainsworth, G. C. \& BisBy, G. R. (1950). A Dictionary of the Fungi. Kew, Surrey: The Commonwealth Mycological Institute.

Bandury, G. H. (1955). Physiological studies in the Mucorales III. The zygotropism of zygophores of Mucor mucedo Brefeld. J. exp. Bot. 6, 235.

BartniCKI-GARCIA, S. (1963). Symposium on biochemical bases of morphogenesis in fungi. III. Mold-Yeast dimorphism of Mucor. Bact. Rev. 27, 293.

BEGA, R. V. (1960). The effect of environment on germination of sporidia in Cronartium ribicola. Phytopathology 50, 61.

Bistis, G. (1956). Sexuality in Ascobolus stercorarius. I. Morphology of the ascogonium; plasmogamy; evidence for a sexual hormonal mechanism. Am. J. Bot. 43, 389.

BRANDT, W. H. (1963). Dimorphism and interactions between the Oakwilt fungus and associated fungi. Plant dis. Rep. 47, 579.

Cantino, E. C. (1966). Morphogenesis in aquatic fungi. In The Fungi, vol. 2. New York, London: Academic Press.

ChIN, B. \& KNIGHT, S. G. (1963). Stimulation of glucose metabolism in Trichophyton mentagrophytes during incubations in increased carbon dioxide tensions. J. gen. Microbiol. 30, I2I.

Clinton, G. P. \& MCCormick, F. A. (1919). Infection experiments of Pinus strobus with Cronartium ribicola. Bull. Conn. agric. Exp. Stn. 214, 428.

Cochrane, V. W. (1958). Physiology of Fungi. New York: John Wiley.

CooKe, W. B. (1962). A taxonomic study in the 'Black Yeasts'. Mycopathol. Mycol. Appl. 17, I.

CROMwell, B. T. (1955). The Alkaloids. In Modern Methods of Plant Analysis, vol. 4. Berlin: SpringerVerlag.

Driver, C. H. \& Wheeler, H. E. (I955). A sexual hormone in Glomerella. Mycologia 47, 3 I I.

Drounet, E. \& MARIAT, F. (1952). Étude des facteurs déterminant le développement de la phase levure de Sporotrichum schenkii. Annls. Inst. Pasteur, Paris 83, 506.

Haskins, R. H. \& SPENCER, J. F. T. (1967). Trichosporonoides oedocephalis gen., n. sp. Can. J. Bot. 45, 515 .

JiLlsON, O. F. \& NiCKERSON, W. J. (1948). Mutual antagonism between pathogenic fungi. Inhibition of dimorphism in Candida albicans. Mycologia 40, 369. 
Langeron, M. \& Guerra, P. (1940). Orientation de la filamentisation des champignons levuriformes cultivés sur lames gélossées. Annls Parasit. h. comp. 17, 580.

LingaPPA, B. T. \& LINGAPPA, Y. (I966a). The nature of self-inhibition of germination of conidia of Glomerella cingulata. J. gen. Microbiol. 43, $9 \mathrm{I}$.

LingaPPA, B. T. \& LINGAPPA, Y. (1966 b). Significance of inhibitory autobiotics of micro-organisms. Abstr. 9th int. Congr. Microbiol., Moscow, p. 223.

LingapPa, B. T. \& LingaPPA, Y. (I967). Alkaloids as self-inhibitors of fungi. Nature, Lond. $214,516$.

Lingappa, B. T., Prasad, M., Lingappa, Y., Hunt, D. F. \& BiemanN, K. (1969). Phenethyl alcohol and tryptophol: Autoantibiotics produced by the fungus Candida albicans. Science, N.Y. $163,192$.

Lodder, J. \& Kreger-VAN RiJ, N. J. W. (1952). The Yeasts. A Taxonomic Study. Amsterdam: New Holland Publishing Co.

Mackinnon, J. E. (1940). Dissociation in Candida albicans. J. infect. Dis. 66, 59.

MAThur, R. S., BARnetT, H. L. \& Lilly, V. G. (1950). Sporulation of Colletotrichum lindemuthianum. Phytopathology 40, 104.

NiCKERSON, W. J. \& BARTNICKI-GARCIA, S. (1964). Biochemical aspects of morphogenesis in algae and fungi. A. Rev. Plant. Physiol. $15,327$.

PIne, L. \& PeAcock, C. L. (1958). Studies on the growth of Histoplasma capsulatum. IV. Factors influencing conversion of the mycelial phase to the yeast phase. J. Bact. 75, 167.

PINe, L. \& WeBster, R. E. (1962). Conversion in strains of Histoplasma capsulatum. J. Bact. 83, 449.

ROBERTS, C. (1946). A comparative study of Torulopsis pulcherrima and Traphrina deformans in culture. Farlowia 2, 345.

Robbins, W. J. (I940). Effect of extracts of Phycomyces upon its development. Am. J. Bot. $27,559$.

RoBInsON, P. M. \& PARK, D. (1965). The production and quantitive estimation of a fungal morphogen. Trans. Br. mycol Soc. $48,56 \mathrm{I}$.

Shriner, R. L., Fuson, R. C. \& CURTIN, D. Y. (1956). The Systematic Identification of Organic Compounds. A Laboratory Manual, $4^{\text {th }}$ ed. New York: John Wiley.

STADleR, D. R. (1952). Chemotropism in Rhizopus nigricans: the staling reaction. J. cell. comp. Physiol. 39, 449.

Sussman, A. S., Coughey, P. \& Strain, J. C. (1955). Effect of environmental conditions upon tyrosinase activity in Glomerella cingulata. Am. J. Bot. 42, 810.

Trione, E. J., Leach, C. M. \& MuTCH, J. T. (I966). Sporogenic substances isolated from fungi. Nature, Lond. 212, 163.

TuRIAN, G. \& MAtikian, N. (I966). Conidiation of Neurospora crassa. Nature, Lond. 212, 1067.

WHEELER, H. E. (1956). Sexual versus asexual reproduction in Glomerella. Mycologia 48, 349.

\section{EXPLANATION OF PLATES}

\section{Plate I}

Auto-inhibition of mycelia and development of Y phase of Glomerella cingulata. Cultures were grown on potato sucrose agar at $2 \mathrm{I}^{\circ}$.

Fig. I. Circularly streaked conidia developed no mycelia along the opposing edges of the streaks whereas the edge of the outermost streak developed advancing cottony mycelia (M). The rest of the streaks proliferated into masses of secondary conidia $(Y)$ on a bed of pseudomycelia (acervuli ?). 9 days. Half actual size.

Fig. 2. Mycelial colony developing from conidia, showing branching hyphae. $24 \mathrm{hr} \times 50$.

Fig. 3. Development of Y phase in sandwiched streak culture. I. Slight mycelia developed from the outer edge but none along the inner edge opposing the second streak. 2. Sandwiched streak opposed by streaks $I$ and 3 developed into $Y$ phase. 3. Streak culture continued to develop $Y$ phase throughout except along exposed edge which developed extensive cottony mycelia. I4 days. Three-fifths actual size.

Fig. 4. Conidia were densely streaked on PS agar slopes made with 2 ml. medium (I), $6 \mathrm{ml}$. medium (2), and $6 \mathrm{ml}$. medium inoculated sparsely with conidia (3). Culture on slope I was yeast-like, on slope 2 partly mycelial, but on slope 3 abundantly mycelial especially on the deep bottom portion of the slope. Half actual size. 

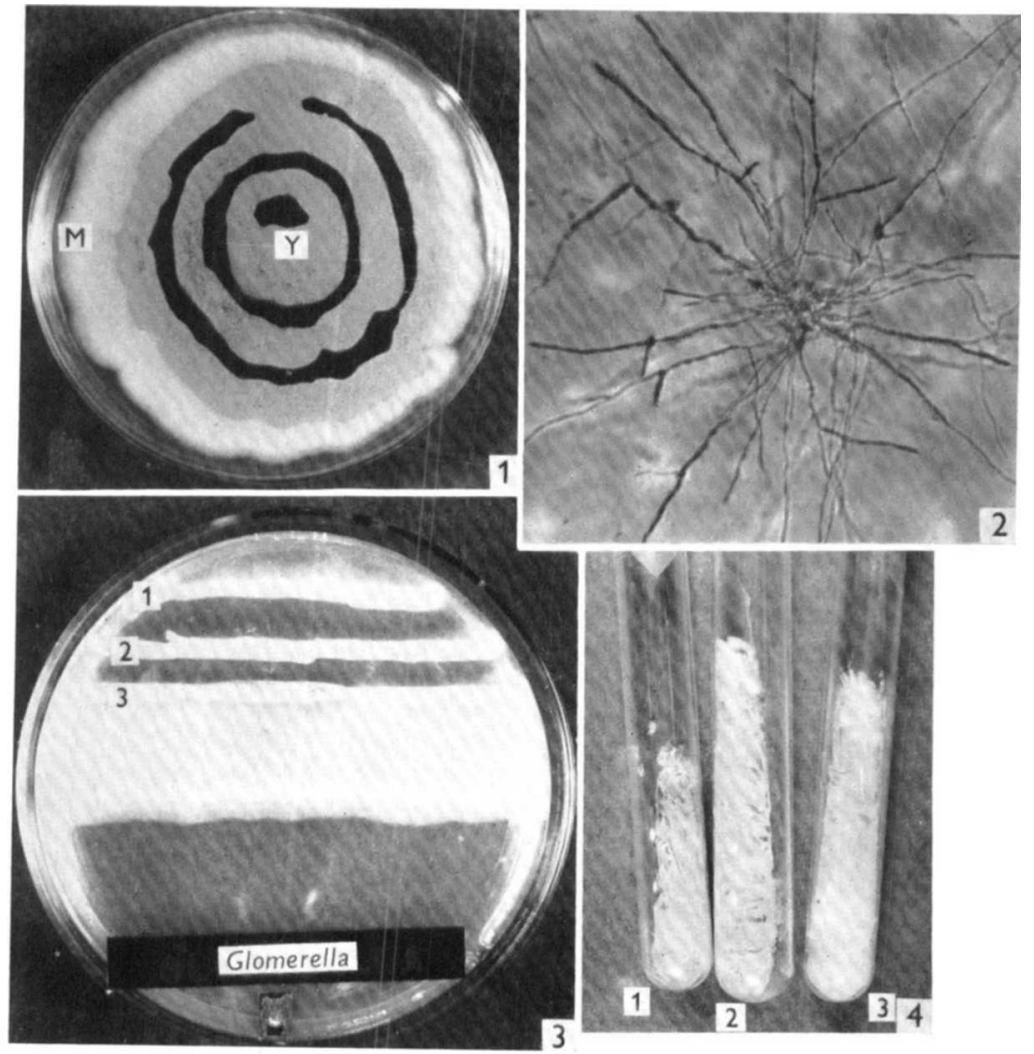

$\sqrt{3}$

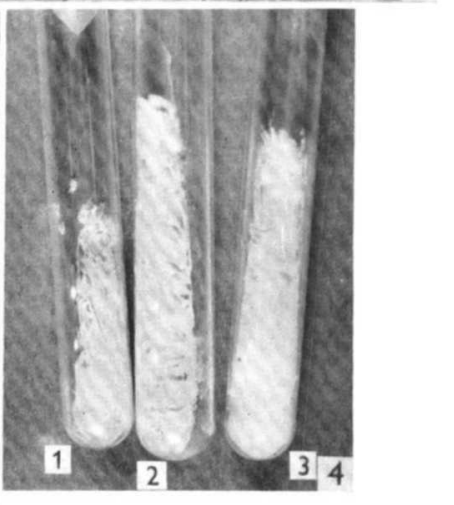


Journal of General Microbiology, Vol. 56, No. I

Plate 2
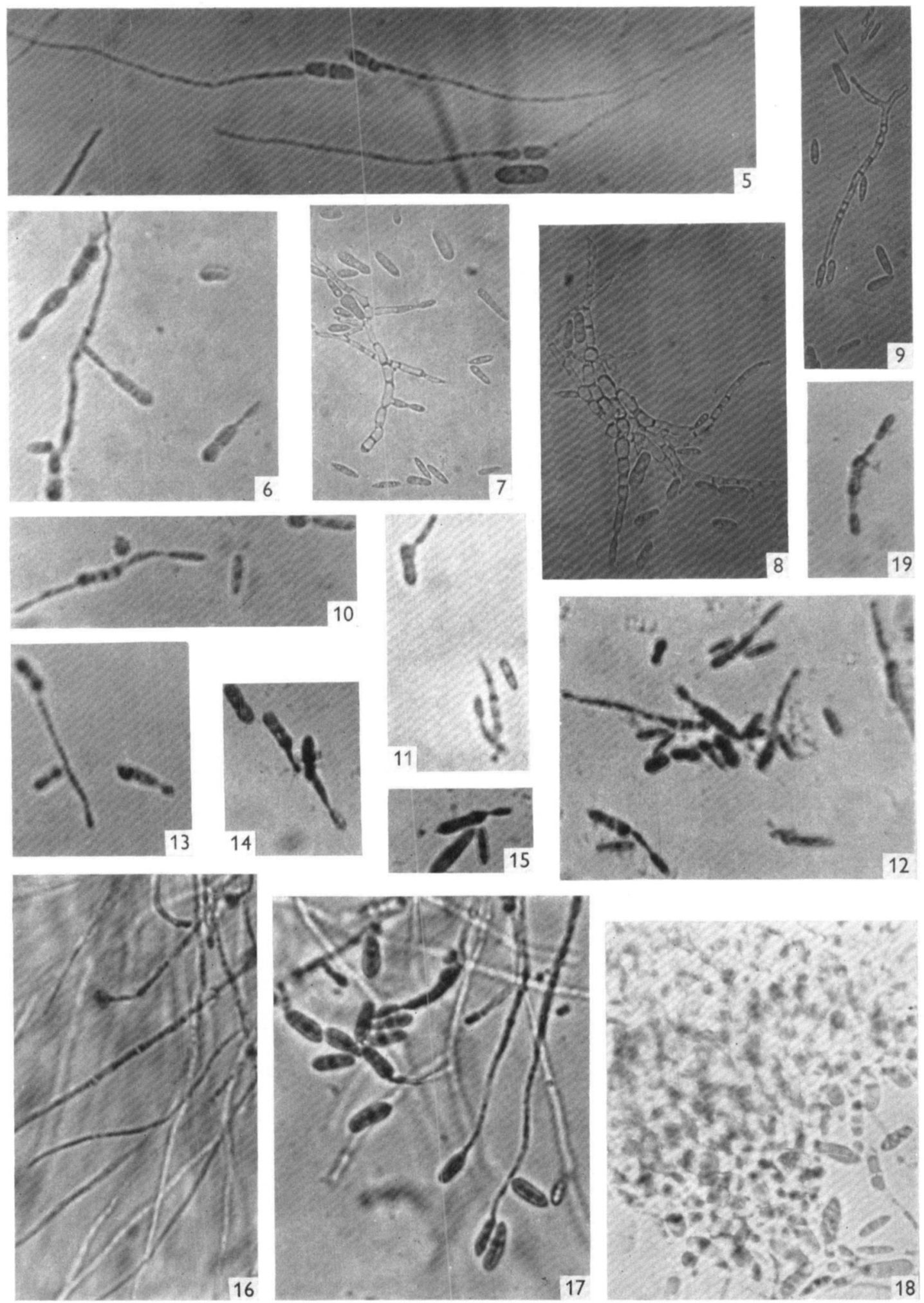

B. T. LINGAPPA AND Y. LINGAPPA 
Plate 2

Developmental stages in $\mathrm{Y}$ and $\mathrm{M}$ phases of Glomerella cingulata.

Fig. 5. Development of germtubes in cultures that gave rise to cottony mycelia. $\times 350$.

Fig. 6. Budding conidia. $\times 350$.

Fig. 7-9. Pseudomycelia and secondary conidia. $\times 350$.

Fig. 10-1 5. Formation of secondary conidia. $\times 350$.

Fig. 16. Margin of mycelial growth of Pl. I, fig. 3, showing vegetative growth. $\times 350$.

Fig. 17. Margin of inhibited mycelial growth of Pl. 1, fig. 3, showing hyphal tips differentiating conidia $48 \mathrm{hr}$ after germination. $\times 350$.

Fig. I 8. Masses of conidia in the Y phase cultures. Pl. I, fig. I, Y. $\times 350$.

Fig. 19. Bipolar budding of conidium. $\times 350$. 